\title{
Racine, "Cahiers de Littérature Française», IV, vol. diretto da Gabriella Violato e Francesco Fiorentino
}

Daniela Dalla Valle

\section{(2) OpenEdition}

1 Journals

\section{Edizione digitale}

URL: http://journals.openedition.org/studifrancesi/9196

DOI: $10.4000 /$ studifrancesi.9196

ISSN: 2421-5856

\section{Editore}

Rosenberg \& Sellier

\section{Edizione cartacea}

Data di pubblicazione: 1 juin 2008

Paginazione: 181

ISSN: 0039-2944

\section{Notizia bibliografica digitale}

Daniela Dalla Valle, «Racine, «Cahiers de Littérature Française», IV, vol. diretto da Gabriella Violato e Francesco Fiorentino", Studi Francesi [Online], 154 (LII | I) | 2008, online dal 30 novembre 2015, consultato il 13 janvier 2021. URL: http://journals.openedition.org/studifrancesi/9196 ; DOI: https:// doi.org/10.4000/studifrancesi.9196

Questo documento è stato generato automaticamente il 13 janvier 2021.

\section{(c) (†) $\ominus$}

Studi Francesi è distribuita con Licenza Creative Commons Attribuzione - Non commerciale - Non opere derivate 4.0 Internazionale. 


\title{
Racine, «Cahiers de Littérature Française», IV, vol. diretto da Gabriella Violato e Francesco Fiorentino
}

\author{
Daniela Dalla Valle
}

\section{NOTIZIA}

Racine, «Cahiers de Littérature Française», IV, oct. 2006, vol. diretto da Gabriella vIOLATO e Francesco FIORENTINo, Università degli Studi di Bergamo, Université Paris Sorbonne, pp. 224.

1 Segnaliamo con un po' di ritardo questo numero dei «Cahiers de Littérature Française», pubblicato come seguito alle manifestazioni del millenario raciniano, raccogliendo una serie di articoli italiani e stranieri, sull'onda della rivisitazione dell'opera del grande tragico. Oltre ai saggi dei due organizzatori del volume, Gabriella violato e Francesco FIORENTINO, dedicati l'uno ad Andromaque (Scènes de 'première vue' dans le théâtre tragique de R.: l'exemple d'Andromaque - impostato sul ricordo di Jean Rousset), l'altro a Bérénice (La tragédie de la communication. Lecture de Bérénice), alcuni dei testi inseriti si concentrano su una singola opera raciniana: molti su Bérénice: Delia GAMBELLI (a proposito di sottili, possibili contatti con gli Amants magnifiques), Solange M. GUÉNOUN (sulla trasformazione di una Bérénice, «infâme judéenne-palestinienne», in una «illustre héroïne de la Comédie Française», da parte di Corneille e di Racine); Georges Forestier (la cui recente edizione raciniana è regolarmente usata in tutto il volume, che si sofferma ad analizzare la vita teatrale della fine del xvII e dell'inizio del xVIII secolo, per smentire l'attribuzione a Racine di un attacco alla Judith di Boyer); uno su Britannicus: Fabrice WILHELM, che analizza la tirannia del rimorso di Nerone; uno su Iphigénie: Flavia MARIOTTI, autrice poi di una traduzione italiana della stessa opera, 
sull'eidôlon d'Iphigénie; uno su Phèdre: Ronald TOBIN, che si sofferma a scoprire il Secret de Phèdre. Non limitato a una sola opera è invece il campo di ricerca di altri lavori, come quelli di Alain GÉNETIOT - Lyrisme galant et amour tragique chez Racine -, di Benedetta PAPASOGLI - Racine. Mémoire et langage -, di John CAMPBELL - Du bon usage et dela crainte -, di Alberto BERETTA ANGUISSOLA - Le texte caché racinien: doutes et hypothèses -, di Fabrice PREYAT - Racine et Perrault devant la conversion de la littérature officielle. Institutions, stratégies, trajectoires -. Un nuovo piccolo convegno su Racine poteva essere costruito con le comunicazioni raccolte in questo numero! Tutti i testi sono in francese. 